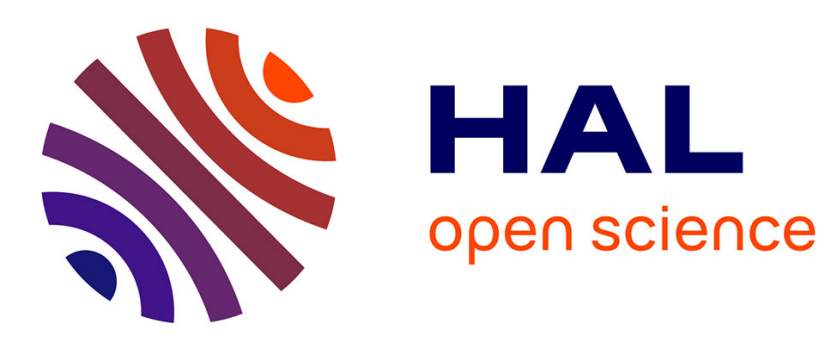

\title{
Carbon intensity of French shippers
}

Christophe Rizet, Cécilia Cruz, Matthieu de Lapparent, Martine Vromant

\section{To cite this version:}

Christophe Rizet, Cécilia Cruz, Matthieu de Lapparent, Martine Vromant. Carbon intensity of French shippers. Transport Research Arena, Apr 2014, Paris, France. pp.10. hal-01128356

\section{HAL Id: hal-01128356 https://hal.science/hal-01128356}

Submitted on 9 Mar 2015

HAL is a multi-disciplinary open access archive for the deposit and dissemination of scientific research documents, whether they are published or not. The documents may come from teaching and research institutions in France or abroad, or from public or private research centers.
L'archive ouverte pluridisciplinaire HAL, est destinée au dépôt et à la diffusion de documents scientifiques de niveau recherche, publiés ou non, émanant des établissements d'enseignement et de recherche français ou étrangers, des laboratoires publics ou privés. 


\title{
Carbon intensity of French shippers
}

\author{
Christophe Rizet $^{\mathrm{a}^{*}}$, Cecilia Cruz, Matthieu de Lapparent ${ }^{\mathrm{a}}$, Martine Vromant $^{\mathrm{b}}$ \\ ${ }^{a}$ University Paris-Est Ifsttar AME DEST, Marne la Vallée France \\ ${ }^{b}$ CETE Nord-Picardie, Lille, France
}

\begin{abstract}
To estimate $\mathrm{CO}_{2}$ emitted by a French shipper for the transportation of its shipments, we use the French shipper survey. In this survey, we only have three shipments per shipper and carbon intensity per shipment is highly variable. So the $\mathrm{CO}_{2}$ per shipper was estimated indirectly, with two different approaches: First we set up a typology of the shippers, in 10 types of 'homogenous' establishments and estimated in each type an average level of emissions per shipper. In a second approach, carbon intensity per tonne shipped has been modelled, using only the shipper characteristics as explaining variables. Then for each shipper, multiplying this average $\mathrm{CO}_{2}$ emission per tonne per its yearly tonnage shipped gave the amount of emissions for its shipments during that year. The two approaches gave reasonably similar results. On average, a French shipper emits a little more than $620 \mathrm{t}$ per year for the transport of its shipments, and this quantity varies from $78 \mathrm{t}$ for the 'lower emitter's type' up to $4700 \mathrm{t}$ for the 'upper' type.
\end{abstract}

Keywords: Green-House Gas, freight transport, shipper emissions.

\section{Résumé}

Pour estimer les émissions de $\mathrm{CO}_{2}$ d'un chargeur français pour son transport, nous utilisons l'enquête française auprès des chargeurs. Nous ne disposons dans celle-ci que de trois envois par chargeur, dont l'intensité carbone est très variable. Aussi, nous avons estimé le $\mathrm{CO}_{2}$ par chargeur indirectement, avec deux approches différentes : d'abord nous construisons une typologie des chargeurs en 10 types d'établissements 'homogènes' et estimons dans chaque type un niveau moyen d'émissions par chargeur. En deuxième approche, nous modélisons le niveau d'émission par tonne expédiée, avec les caractéristiques du chargeur pour seules variables explicatives. Pour chaque chargeur, le produit de ce niveau moyen d'émission d'une tonne par le tonnage annuel transporté donne une estimation de son niveau annuel d'émissions. Les résultats obtenus par ces deux approches sont raisonnablement proches : un établissement émet en moyenne, un peu plus de $620 \mathrm{t}$ par an pour le transport de ses expéditions, et cette quantité varie de $78 \mathrm{t}$ pour les établissements du type 'faiblement émetteurs' jusqu'à 4700 t pour le type des 'gros émetteurs'.

Mots-clé: Gaz à effet de serre, transport de marchandises, établissement chargeur.

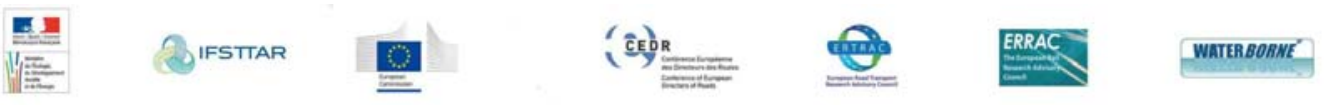




\section{Introduction : context and objective}

Over one quarter of greenhouse gas (GHG) emissions in France comes from the transport sector and this share is growing. Furthermore, within the transport sector, the share of emissions from freight activity is growing and there is no sign of saturation (EMEP/EEA, 2010). Therefore deep changes are necessary to reach the target of dividing per 4 the anthropological GHG emissions, either through carbon efficiency improvements or by means of reduction of transport demand. The link between transport emission and climate change has been analysed in Schwanen et al. (2011); we are here focusing on freight carbon intensity.

Carbon efficiency of freight transport and also the determinants of freight transport demand are not well understood. We claim that an in-depth knowledge of the factors that influence firms in their logistical choices as well as the factors that influence carbon efficiency would make freight GHG mitigation much easier. This lack of knowledge is due to several factors, including the theoretical complexity of the problem, the insufficiency of resources that have been made available for freight compared with passenger transport, and the inadequacy of the existing data. The French shipper survey developed in 2004 is an attempt to fill this gap in data. The survey methodology is discussed in Rizet et al. (2004); Guilbault \& Gouvernal (2010) give an overview of the results.

Our objective in this paper is, using this survey, to estimate the level of $\mathrm{CO}_{2}$ emissions and carbon efficiency of freight transport per shipper. After presenting the survey (section 2) and developing the way we estimated transport energy consumption and $\mathrm{CO}_{2}$ emission per shipment (section 3), we present the two ways we used to estimate the yearly quantity of freight transport $\mathrm{CO}_{2}$ emissions per shipper. First, we set up a typology of shippers, got 10 types of 'homogenous' shippers and estimated in each type an average level of emissions per shipper (section 4). In a second approach, we set up a model explaining the $\mathrm{CO}_{2}$ emission per tonne shipped, using only the shipper characteristics as explaining variables. Multiplying this average $\mathrm{CO}_{2}$ emission per tonne of the shipper per the yearly tonnage gives us the amount of emissions of this shipper for his shipments during that year (section 5). Then we compare the shipper emissions estimated through these two approaches and consider the variability of carbon efficiency among shippers (section 6).

\section{Data : the 2004 French shipper survey}

The two major characteristics of the French shipper survey are the description of the shippers' organizational features influencing the transport choices and the tracking of a selection of shipments from their departure from the plant up to their arrival to the consignee. In this survey, information is collected at three levels:

- Shipper establishment: after a few questions about the volume and structure of the company's ingoing and outgoing transport flows and its own fleet of vehicles, a face-to-face interview is administered to the logistics manager of the company. The questions concern the economic characteristics of the firm: production, distribution, storage practices, relationships with its customers and suppliers, and the management and communications systems it uses. A “transport" section is added to this description of the firm's industrial and logistical organization. It deals with the firm's relationships with carriers, terms of access to the various types of infrastructure, and how responsibility for transport is shared between the firm and its partners.

- Shipment level: at the end of the establishment questionnaire, the last 20 shipments are listed, of which 3 are randomly selected and then traced until they reach their final consignee. The consignment questionnaires are filled in either with the manager mentioned above or with the manager in charge of dispatching; they deal with the economic relationship between the shipper and the consignee and the terms of business between the two. This relationship between the shipper and his clients is described not only through the physical and economic characteristics of the shipment but also with information about the quantity of goods sent to this client per year (yearly tonnage to this consignee), the yearly number of shipments to this consignee, the split of responsibilities with regard to transport organization and the contractual allocation of transport costs and associated services. The first information required in order to reconstruct transport chains is also collected at this level, with the identification of the consignee.

- Transport operator and journey link: for this part of the survey, questionnaires are administered by telephone. Questions deal with the economic characteristics of the operator, including the operator to whom it handed the 
shipment and with the characteristics of the transport leg: mode and vehicle type, load, etc. The next operator is in turn questioned up to the final consignee and the description of the whole transport chain. The transport chain is split into as many legs as there are changes to another vehicle.

The transport chain is therefore reconstructed throughout Western Europe and includes an interview with the consignee. For a shipment which travels beyond the limit of Western Europe, the transport chain is surveyed only until the first transfer point after the frontier of Western Europe. Furthermore, the 2004 shipper survey has been adapted to enable the quantification of energy consumed and $\mathrm{CO}_{2}$ emitted, and to relate them to the determinants of freight transport demand (Rizet et al., 2004). Primary and final energy consumption have been computed per leg, as the product of distance per vehicle energy consumption (for trucks: litres per km), divided per the load and multiplied per the shipment weight; empty backhauling is estimated using the results of the French national freight vehicles survey. Energy consumption is converted in grams of oil equivalent (goe) and shipment energy consumption is the sum of energy per leg. Both Tank to Wheel (TW) and Well to Wheel (WW) $\mathrm{CO}_{2}$ emissions are then computed as the product of energy per an emission factor. Dividing $\mathrm{CO}_{2}$ per the tonnekilometre of the shipment gives the carbon efficiency of the shipment, in $\mathrm{kg} \mathrm{CO}_{2} / \mathrm{tkm}$. The method to compute $\mathrm{CO}_{2}$ per shipment is described in Rizet et al. (2013). In this paper we present the ways we estimated the yearly quantity of freight transport $\mathrm{CO}_{2}$ emissions per shipper. This was done with two approaches: First we set up a typology of shippers, in 10 types of 'homogenous' shippers and estimated the average level of $\mathrm{CO}_{2}$ emissions in each type; in the second approach, we modelized the carbon intensity per tonne shipped and multiplied this per the yearly tonnage shipped by a shipper.

\section{Estimating shipper yearly emissions from a typology of shippers}

In the survey, the sample of shipments is obtained by a first sampling among shippers (about 3000 surveyed shippers) and a second sampling of shipments among the surveyed shippers. Only three shipments are surveyed per shipper on average, which does not allow estimating directly the volume of emissions of this shipper. So we grouped a significant number of shippers having 'profiles' as close as possible, to obtain a number of shipments which allows to estimate the volume of emissions of this type of shippers.

\subsection{A typology of shipper establishments}

Our objective thus is to establish a typology of establishments using the variables which characterize the volume of emissions of these shippers. After different tries, we finally used a typology realized by 'analysis of the multiple correspondences' (AMC) and a 'non hierarchical classification', in 10 types (Clausen, 1998). We used the following variables:

- The number of employees

- The annual number of shipments

- The distribution of all the shipments according to their weight,

- The distribution of all the shipments according to their destination,

- The distribution of all tons shipped according to the main transport mode.

AMC allows realizing a typology based on the resemblance. Two establishments will be close all the more as they possess a large number of modalities (variables) together. The observation also concerns the association between modalities. We did it with the SAS CORRESP procedure. The output of this procedure is a set of new variables which correspond to the coordinates of the individuals (establishments) and the variables in a multidimensional space. This space is defined by more or less numerous axes according to the number of variables or the quality of the analysis. The quality of the explanation of the cloud of points will be a function on behalf of slowness of this cloud which is explained by axes. For the classification we used 6 axes, what brings the part of slowness explained to $51 \%$. The typology is then realized by the method of classification of dynamic clouds applied to the coordinates of the establishments on each of these axes.

The next step is to group shippers by types, according to their positioning on the axes. Two establishments close according to these axes will be grouped in the same type. The dynamic clouds method is then applied to the coordinates of shippers on each of these axes.

Shippers are grouped in a limited number of types in such a way that the establishments of the same group are alike from the point of view of variables used for the analysis. We chose to limit to 10 the number of types. 
Starting from 10 cores and by successive iterations, the procedure supplies a set of types by grouping the closest establishments there. The SAS CLUSTER and FASTCLUS procedures were used to define the types from the coordinates stemming from the AMC. We so obtained 10 types of shippers with more than 200 shippers in each type, plus a group of 120 shippers with missing variables, classified as 'without type'.

\subsection{Estimating the quantity of freight transport $\mathrm{CO}_{2}$ emissions per shipper of each type}

For each type of establishments so obtained we calculate then (cf. table 1 below):

- The total quantity of $\mathrm{CO}_{2}$ emissions of freight transport as the weighted sum of the emissions of the shipments of this type;

- The average emissions of an establishment of this type, by dividing the total emissions of the type by the weighted population of establishments.

Levels of emissions are very variable among types. Biggest emitters are in Type 2 with on average 4764 tonnes of $\mathrm{CO}_{2}$ per year for the transportation of their shipments; the lowest emitters are in type 1, with an average of 79 tonnes per establishment and per year. To appreciate the dispersal of these values of average emissions per shipper according to the type, we calculated for each type, the ratio between the average emissions per shipper of this type to the emissions of the least emitting type shipper (i.e. type 1): according to this ratio (last column in table 1), an establishment of type 2 emits on average 56 times more that an establishment of type 1 . The various types do not all differ significantly by their average level of emissions: types 5 and 9 on the one hand and types 7 and 10 on the other hand seem to have close levels of yearly emissions.

Table 1 : The 10 types of shippers and their $\mathrm{CO}_{2}$ Emissions

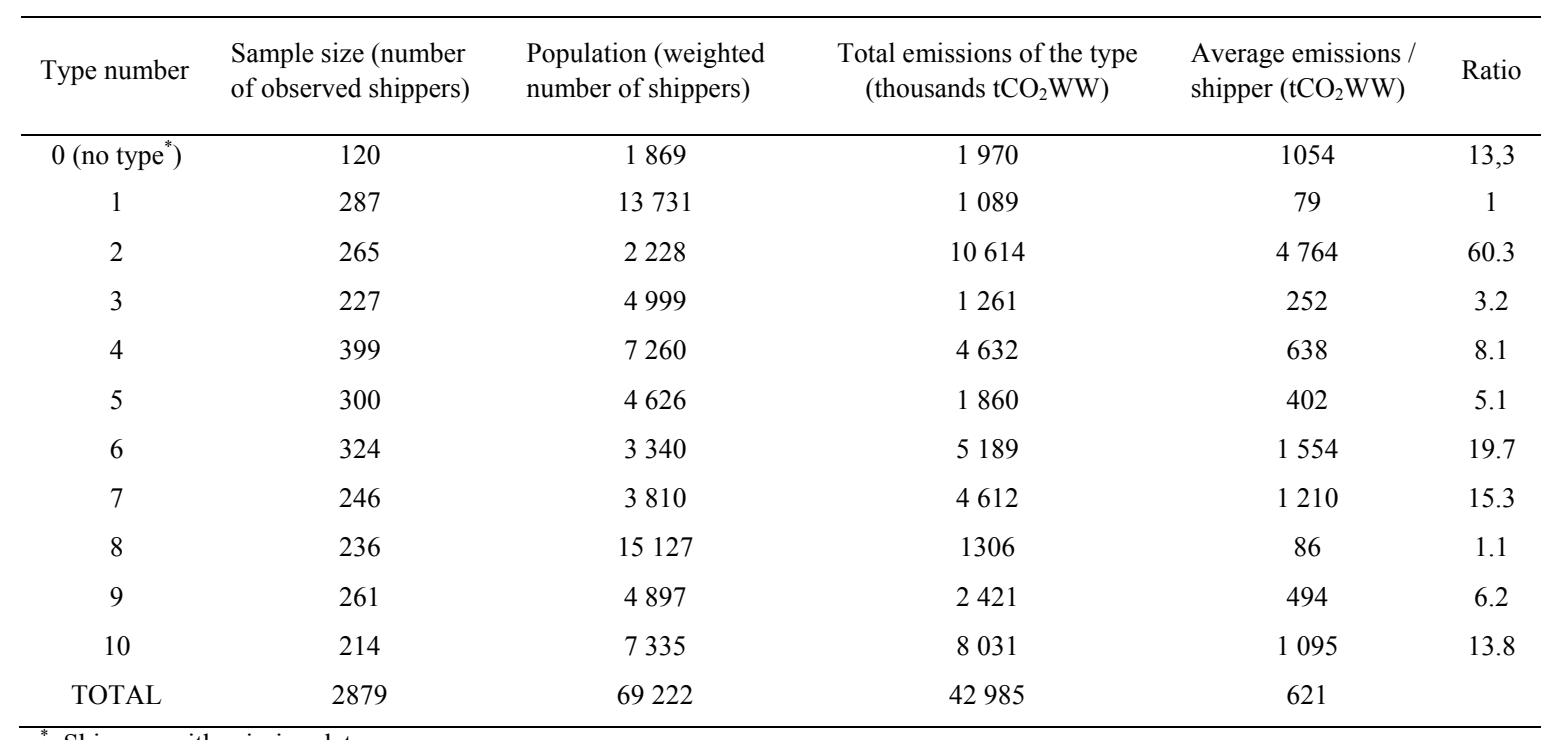

${ }^{*}:$ Shippers with missing data

\subsection{Precision of the estimated quantity of $\mathrm{CO}_{2}$ per shipper}

To calculate the precision of this estimator, we used the 'bootstrap' method: in each type we randomly sampled important groups of establishments and, on each of these sub-samples we calculated a new value of the $\mathrm{CO}_{2}$ by establishment with the previous method. The distribution of these indicators from the various sub-samples of the same type allows us to calculate the precision of the estimation of the $\mathrm{CO}_{2}$ per shipper of this type. The SAS SURVEYSELECT procedure allows making this poll of sub-samples and so facilitates this method of 'bootstrap'. Figure 1 shows the distribution of the average $\mathrm{CO}_{2}$ by establishment so estimated in the various subsamples of type 1 . 


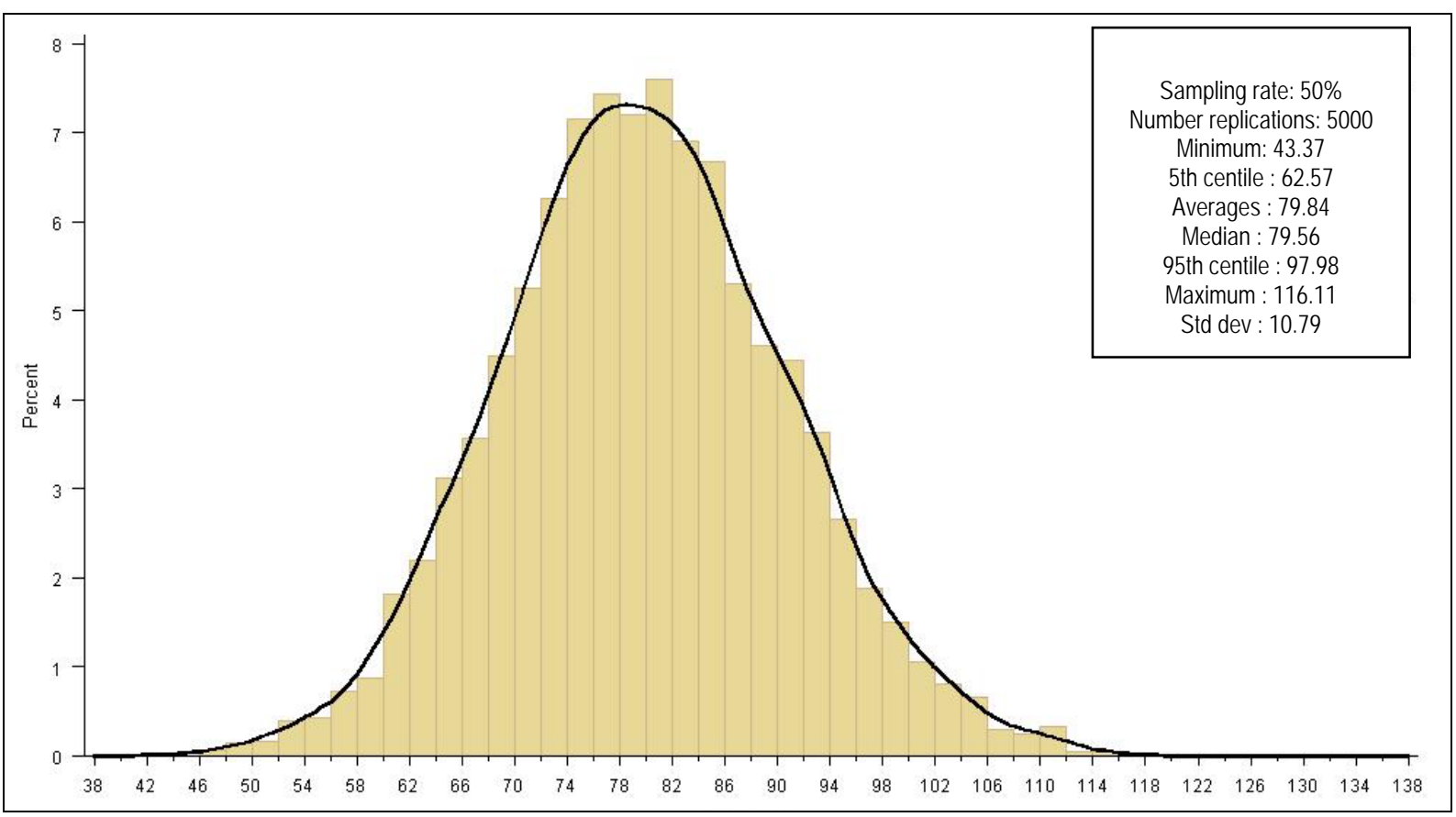

Figure 1 : Distribution of the estimators of $\mathrm{CO}_{2}$ per shipper of type 1 , in $\mathrm{tCO}_{2} /$ shipper / year

The average values and the standard deviation of these estimators resulting from the bootstrap, enable to calculate the limits of the $95 \%$ confidence interval. These limits are shown for each type in figure 2 here under.



Figure 2: Precision of the $\mathrm{CO}_{2}$ estimator per shipper according to his type in $\mathrm{tCO}_{2}$ /shipper (the blue bars correspond to the minimum of the confidence interval and the red ones to the maximum)

Figure 2 shows that only the type 2, with an average of $4770 \mathrm{t}$ of $\mathrm{CO}_{2}$ per shipper and per year clearly differs from other types for the volume of emissions. Types 1 and 8, who have a low level of emissions, are very close one of the other, with an average of respectively 80 and $87 \mathrm{t}$. and confidence intervals which widely recover. Confidence intervals of the other types also recover: types $3,4,5$, and 9 on the one hand and types 6,7 and 10 on the other hand. 


\section{Estimating shipper yearly emissions with a model of carbon intensity per tonne shipped}

We want to develop and calibrate a model linking the $\mathrm{CO}_{2}$ emitted by the transport to the shipper characteristics. If we disregard the estimation of the levels of emissions by type of shippers, transport $\mathrm{CO}_{2}$ emissions are known for shipments. So, various models were tested to explain the carbon intensity of a shipment by the characteristic of the shipper. As far as the only explanatory variables are the shipper characteristics, such a model enables to estimate the average carbon intensity of a shipment from this shipper and, by multiplying this carbon intensity per the number of shipments, to estimate the total emissions of this shipper per year. In practice, we modelled the carbon intensity per tonne shipped rather than per shipment.

\subsection{A model of carbon intensity per tonne shipped}

Two quantities are known for all shippers and could allow estimating their freight transport emission: the yearly number of shipments and yearly tonnage shipped. After various tries, we decided to model the carbon intensity per tonne, rather that the intensity per shipment, because the estimate is more accurate. Various forms of models were tested, in particular combinations of logarithms and levels.

The potential explanatory variables are the characteristics of the shipper from the survey, in order to be able to estimate an average level of carbon intensity per tonne for each shipper, independently of the characteristics of the shipment. In these 300 available variables, about 15 were found explanatory without counting too many missing. The class variables have been transformed in dummies. The final model is:

$\log \left(\mathrm{CO}_{2} /\right.$ tonne $)=\mathrm{a} 1 * \mathrm{x} 1+\mathrm{a} 2 * \mathrm{x} 2+\mathrm{a} 3 * \mathrm{x} 3+\ldots+\mathrm{a} 15 * \mathrm{x} 15$

Where $\mathrm{x} 1, \mathrm{x} 2, \mathrm{x} 3 \ldots$ are the shipper characteristics.

It is based on 7573 observed shipments with all the explanatory variables; the coefficient of correlation is 0.40 and 14 variables are explanatory at the level of $5 \%$. These 15 variables are the characteristics:

- Of the distribution of the shipper shipments according to their weight (a proxy for the shipment weight);

- Of the distribution of the shipper shipments according to their geographical destination (a proxy for distance);

- Of how much this shipper is using the various transport modes (a proxy for the mode) and

- Of the shipper 'business sector' (a proxy for the type of goods shipped).

Estimated carbon intensity per tonne varies from about ten kilograms to some 3 tonnes with a great majority below one tonne.

\subsection{Precision of the estimated carbon intensity per tonne}

The $95 \%$ confidence interval of carbon intensity was calculated with SAS, using the option ' lclm '= lower limit and ' uclm ' = upper limit. In figure 3 below, every establishment is represented by three points which have for abscissa the estimated $\mathrm{CO}_{2}$ /tonne of the shipper and, for ordered, the same value of carbon intensity per tonne shipped by this shipper, as well as the lower and higher limits of the $95 \%$ confidence interval of this estimated value. To allow a better legibility, the figure 3 focuses on carbon intensities lower than one tonne. 


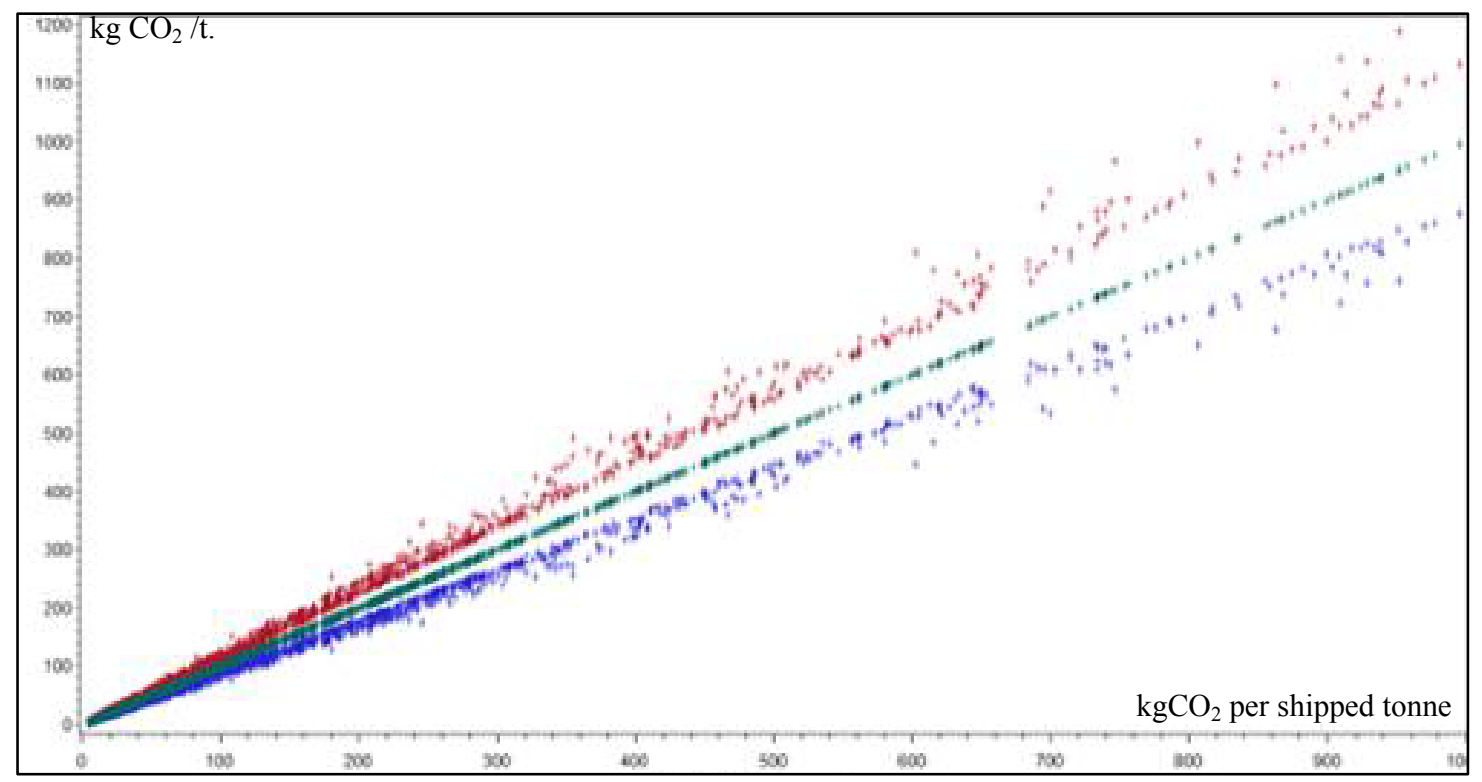

Figure 3: Carbon intensity per tonne shipped and the $95 \%$ confidence intervals

The limits of the confidence interval are about $20 \%$ above and below the estimated value. This confidence interval varies from an establishment to the other one, but this variability is limited itself: there is thus an important difference between establishments on the left of the figure, which emit less than $100 \mathrm{~kg}$ by transported tonne and the establishments on the right, which emit more than $900 \mathrm{~kg}$ by tonne.

\subsection{Carbon intensity per shipper}

The $\mathrm{CO}_{2}$ emitted by a shipper per year is calculated as the product of the $\mathrm{CO}_{2}$ per tonne, estimated by shipper according to the method described above, by the yearly tonnage shipped by this establishment. The yearly tonnage of the shipper is known from the survey so the limits and the confidence interval for the $\mathrm{CO}_{2}$ per shipper are calculated as the product of the limits of the confidence interval of the $\mathrm{CO}_{2}$ by tonne multiplied by the yearly tonnage of the shipper.

\subsection{Precision of the estimated carbon intensity per shipper}



Figure 4 : Estimated tonnes of $\mathrm{CO}_{2}$ per shipper and the $95 \%$ confidence intervals 
According to this approach, the $\mathrm{CO}_{2}$ emitted by a shipper in one year for the transport of its shipments varies from approximately one tonne (on the left of figure 4) up to more than 10000 tonnes (on the right). The confidence intervals are important in absolute value but, considering the dispersal of these estimated values of the $\mathrm{CO}_{2}$ per shipper, it is possible to define groups of establishments clearly differentiated from the point of view of emissions, with little overlapping of the confidence intervals.

\section{Comparison of carbon intensity per shipper estimated by the two methods}

We have now two values of the $\mathrm{CO}_{2}$ emitted by shipper for the transport of its yearly shipments, one established by the typology and the other one by the model. Figure 5 below compares these indicators by type of shippers, for those shippers for which a level of $\mathrm{CO}_{2}$ has been estimated by the two ways. The biggest emitters (shippers of type 2), with $4700 \mathrm{t}$ per year emit 60 times more that those of type $1(78 \mathrm{t}) . \mathrm{A} \mathrm{CO}_{2}$ mitigation policy aiming at shippers should clearly focus on these 'big emitters'. On average the $\mathrm{CO}_{2}$ emitted by a shipper is a little more than $620 \mathrm{t}$ a year.

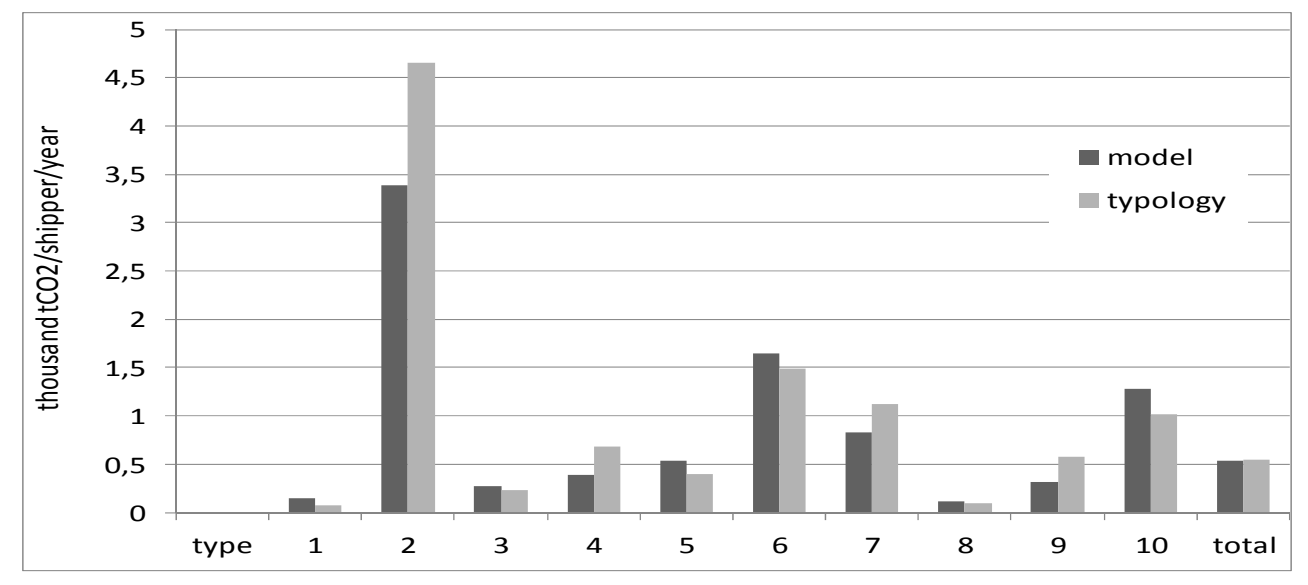

Figure 5 : A comparison of shipper carbon intensity estimated by the two ways

\section{Carbon intensity, carbon efficiency and the impact of a carbon tax on a shipper competitiveness}

To quantify $\mathrm{CO}_{2}$ emitted by shippers is important for assessing the potential impact of a carbon tax policy. If we consider that such a carbon tax would be distributed on all the tonnes sold by this company, then the main indicator for the impact on shipper competitiveness should be the shipper $\mathrm{CO}_{2}$ per tonne, i.e. its carbon efficiency. If we now consider that the amount of carbon taxes will be used to reduce the cost of labour (health, unemployment, and pension), in order to improve the competitiveness of the national workers, then the benefit of such a policy for a company would be proportional to its number of employees: the more employees, the more cost reduction.

Our 10 types of shippers not only have different carbon intensity per shipper and per employee but they also correspond to different carbon efficiencies per tonne (from 12 up to $208 \mathrm{~kg} \mathrm{CO}_{2} /$ tonne) and per tkm. Carbon efficiency per tkm is less variable (from 0.046 up to $0.678 \mathrm{~kg} \mathrm{CO} / \mathrm{tkm}$ ). By employee, the average level of emission, is $16.5 \mathrm{t} \mathrm{CO}_{2}$ per year and varies from $4.3 \mathrm{t}$ for type 10 up to $27.2 \mathrm{t}$ for type 9 that is a 1 to 6 ratio. 


\begin{tabular}{llccccc}
\hline \multirow{2}{*}{ Type } & \multirow{2}{*}{$\mathrm{N} \mathrm{Obs}$} & Thousands $\mathrm{tCO}_{2}$ & \multicolumn{2}{c}{$\mathrm{tCO}_{2}$ emitted } & \multicolumn{2}{c}{$\mathrm{kgCO}_{2}$ emitted } \\
& & & per shipper & per employee & per shipped tonne & per tkm \\
\hline 0 & 120 & 1970 & 1054 & 13.0 & 28.9 & 0.078 \\
1 & 287 & 1089 & 79 & 4.3 & 11.8 & 0.110 \\
2 & 265 & 10614 & 4764 & 12.3 & 89.6 & 0.111 \\
3 & 227 & 1261 & 252 & 4.4 & 61.0 & 0.102 \\
4 & 399 & 4632 & 638 & 9.6 & 52.3 & 0.124 \\
5 & 300 & 1860 & 402 & 6.9 & 18.5 & 0.082 \\
6 & 324 & 5189 & 1554 & 7.9 & 44.8 & 0.046 \\
7 & 246 & 4612 & 1210 & 16.5 & 24.0 & 0.136 \\
8 & 236 & 1306 & 86 & 4.7 & 59.5 & 0.151 \\
9 & 261 & 2421 & 494 & 6.1 & 38.6 & 0.089 \\
10 & 214 & 8031 & 1095 & 27.2 & 208.4 & 0.678 \\
Total & 2879 & 42985 & 621 & 10.2 & 46.7 & 0.108 \\
\hline
\end{tabular}

Table 2 : carbon intensity and carbon efficiency per type of shipper

Indeed, these four indicators give rather different views of the burden of a freight transport carbon tax among the different types of shippers.

- A transport carbon tax might be supported by the shippers according to their level of emissions. With a tax of $100 €$ per $\mathrm{tCO}_{2}$ for example, the tax per shipper would range from $7900 €$ for shippers of type 1 up to $476400 €$ for shippers of type 2 .

- These shippers have very different levels of sales or shipments; related to their tonnage shipped a tax of $100 €$ per $\mathrm{tCO}_{2}$ would then range from $1.18 €$ /sold tonne for shippers of type 2 up to $20.8 € /$ sold tonne for shippers of type 10 .

- If the product of this carbon tax is used to reduce the cost of labour, the benefiters would then be the big employers. The number of employees is then an indicator of the cost reduction for the shipper of such a policy.

- The ratio $\mathrm{tCO}_{2}$ emitted per employee is then a good indicator of the real cost for a given shipper or type of shipper. Multiplied per the ratio [ $\operatorname{tax}\left(\right.$ in $€ / \mathrm{tCO}_{2}$ ) / labour cost reduction (in $€ /$ employee), it gives an idea of the impact of such a policy for this type of shippers. If the product of these 2 ratios equal one, the benefit is as important as the cost. If this product is higher than one then the cost is higher than the benefit; and if this product is smaller than one, then the reduction of cost is more important than the tax paid. We don't know the ratio 'tax per tonne/reduction of cost per employee' but we can make the hypothesis that this ratio will be identical for all shippers. Then the comparison of the $\mathrm{tCO}_{2} /$ employee ratio is an indicator of the split of the burden among the different shippers. The winners of such a policy would then be the shippers of type 1, 3 and 8 ; the shippers of type 10 would be the main loosers.

- Carbon efficiency, gives another view of the comparison of emissions between very heterogeneous shippers. Type 10 for example has e very low carbon efficiency per tonne and per tkm.

\section{Conclusion :}

$\mathrm{CO}_{2}$ emissions per shipper has been estimated with two different approaches, using the French shipper survey data: First we set up a typology of the shippers, in 10 types of 'homogenous' establishments and estimated in each type an average level of emissions per shipper. In a second approach, carbon intensity per tonne shipped has been modeled, using only the shipper characteristics as explaining variables. Then for each shipper, multiplying this average $\mathrm{CO}_{2}$ emission per tonne per its yearly tonnage shipped gave the amount of emissions for its shipments during that year. The two approaches gave reasonably similar results.

This in depth knowledge of the shipper $\mathrm{CO}_{2}$ emissions can be used to compare the carbon efficiency of different types of shippers and the impact of a carbon tax applied to freight transport on shipper's competitiveness. Four indicators of carbon performance have been quantified that give very different results for our ten types of shippers: 
Carbon intensity per shipper and per year varies from $78 \mathrm{tCO}_{2}$, for the 'lower emitter type' up to $4700 \mathrm{t}$ for the 'upper' type. The average is $620 \mathrm{tCO}_{2}$ per shipper and per year and a shipper of the 'upper' type emits 60 times more $\mathrm{CO}_{2}$ than the 'lower' ones.

The ten types of shippers also have very different carbon intensities per tonne: from 12 up to $208 \mathrm{kgCO}_{2} /$ tonne (a 1 to 17 ratio) with an average of $46.7 \mathrm{kgCO}_{2} /$ tonne.

Per tkm, carbon intensity varies according to the shipper types, from 46 up to $678 \mathrm{gCO}_{2} / \mathrm{tkm}$, i.e. a 1 to 15 ratio, with an average carbon intensity of $108 \mathrm{gCO}_{2} / \mathrm{tkm}$.

Finally, carbon intensity per employee could be important, if the carbon taxes receipt would be used to reduce the indirect cost of labour: shippers would pay taxes proportionally to their emissions and would benefit reduction of labour costs, according to their number of employees. Then group of shippers' $\mathrm{n}^{\circ} 1$, with a ratio of $4.3 \mathrm{tCO}_{2}$ per employee per year would be the winners while shippers of group 10, which have a ratio of 27.2 $\mathrm{t} / \mathrm{employee}$, would be the main losers of such a policy

\section{Acknowledgements}

The results presented here are part of an ongoing Ifsttar research program funded by the French Ministry of transport (DGITM); we have used the SAS software for data analysis and figures.

\section{References}

Clausen, S.E. (1998). Applied correspondence analysis. Thousand Oaks (CA): Sage.

EMEP/EEA (2010). Emission inventory guidebook 2009, updated June 2010.

Guilbault M., Gouvernal E. (2010). Transport and Logistics Demand: new input from large shippers surveys in France. Transportation Research Record: Journal of the Transportation Research Board, n 2168, 71-77.

Rizet, C., Armoogum, J. \& P. Marchal (2004). Energy consumption estimation with a shipper \& transport chain survey. Proceedings of the International Conference on Transport Survey Quality and Innovation, Costa Rica.

Rizet, C., Cruz, C. \& Lapparent M. (2013). Impact of logistical choices on freight transport carbon efficiency WCTR 2013 Rio.

Schwanen, T., Banister, D. \& Anable J. (2011). Scientific research about climate change mitigation in transport: a critical review : Transportation Research Part A n45, 993-1006. 